\title{
A MATEMÁTICA NOS PRIMEIROS ANOS ESCOLARES: ELEMENTOS OU RUDIMENTOS? \\ DOI: http://dx.doi.org/10.1590/2236-3459/56670
}

\author{
Wagner Rodrigues Valente
}

Universidade Federal de São Paulo, Brasil.

\section{$\cos 8$}

\section{Resumo}

Este artigo reúne resultados parciais de pesquisa que vêm sendo obtidos pela realização de dois projetos de investigação, um de âmbito nacional e outro internacional. Tais resultados intentam responder à seguinte questão: que trajetórias tiveram as concepções sobre os saberes matemáticos para serem ensinados nos primeiros anos escolares? $O$ trabalho adota como enquadramento teórico referências vindas da História Cultural. Utiliza como base empírica os posicionamentos de personagens condutoras da educação brasileira de finais do século 19 a meados do século 20, lidos em revistas pedagógicas. Buscar-se-á mostrar que os saberes elementares matemáticos seguem um movimento de alternância entre duas concepções: ora eles são vistos na forma de elementos, ora são concebidos como rudimentos. E, ainda, o que parece relevante: esses dois modelos convivem na atualidade.

Palavras-chave: matemática curso primário, aritmética, saber elementar.

\section{MATH IN PRIMARY SCHOOL: ELEMENTS OR RUDIMENTS?}

\begin{abstract}
The paper presents partial results of research that have been obtained by conducting two research projects, a national and an international. These results intend to answer the following question: What trajectories had the conceptions about the mathematical knowledge to be taught in the early school years? The work adopts the theoretical framework coming references of Cultural History. Used as empirical basis the texts of important Brazilian educators of the late nineteenth century to the mid-twentieth century, read in pedagogical journals. Search It will show, since announcing the results, the elementary mathematical knowledge follow an alternating movement between two conceptions: now they are seen as elements, now this knowledge are designed as rudiments. And yet, what it seems relevant: these two models coexist today.

Key-words: elementary school mathematics, arithmetic, elementary knowledge.
\end{abstract}




\title{
MATEMÁTICAS EN LA ESCUELA PRIMARIA: ELEMENTOS O RUDIMENTOS?
}

\begin{abstract}
Resumen
El artículo presenta resultados parciales de la investigación que se han obtenido mediante la realización de dos proyectos de investigación, nacional e internacional. Estos resultados tienen la intención de responder a la siguiente pregunta: ¿Qué trayectorias habían las concepciones sobre el conocimiento matemático que se enseña en los primeros años escolares? El trabajo adopta las referencias teóricas marco procedente de Historia Cultural. Se utiliza como base empírica los textos de importantes educadores brasileños de finales del siglo 19 hasta mediados del siglo 20, leído en revistas pedagógicas. Buscar Se mostrará, desde que anunció los resultados, el conocimiento matemático elemental sigue un movimiento alternativo entre dos concepciones: ahora son vistos como elementos, ahora este conocimiento se ha diseñado como rudimentos. $\mathrm{Y}$, sin embargo, lo que parece relevante: estos dos modelos coexisten en la actualidad.

Palabras-clave: matemáticas de la escuela primaria, aritmética, saber elemental.
\end{abstract}

\section{MATH A L'ECOLE PRIMAIRE: ÉLÉMENTS OU RUDIMENTS?}

\section{Résumé}

Le texte présente les résultats de recherche partiels qui ont été obtenus en effectuant deux projets de recherche, une nationale et une internationale. Ces résultats ont l'intention de répondre à la question suivante: Quelles sont les conceptions de la connaissance mathématique pour être enseigné dans les premières années d'école? Le travail adopte les cadres venant références théoriques de l'histoire culturelle. Utilisés comme base empirique les positions des personnages qui menaient l'éducation brésilien de la fin du $19 \mathrm{e}$ siècle au milieu du $20 \mathrm{e}$ siècle, lu dans des revues pédagogiques. Les résultats montrent que la connaissance mathématique élémentaire suivre un mouvement alternatif entre deux conceptions: à un moment où ils sont considérés comme des éléments; dans un autre, cette connaissance sont conçus comme des rudiments. Et pourtant, ce que il semble pertinent: ces deux modèles coexistent aujourd'hui.

Mots-clé: mathématiques de l'école élémentaire, arithmétique, savoir élémentaire. 


\section{Introdução}

ste texto atém-se à análise dos modos de pensar sobre a matemática a ser ensinada nos primeiros anos escolares. $O$ trabalho orienta-se pela seguinte interrogação: que trajetórias tiveram as concepções sobre os saberes matemáticos para serem ensinados nos primeiros anos escolares? Considera-se como enquadramento teórico-metodológico para a análise, sobretudo, os estudos históricopedagógicos realizados por André Chervel e Alain Trouvé. Buscar-se-á mostrar que os saberes elementares matemáticos seguiram um movimento de alternância entre duas concepções: ora eles foram pensados na forma de elementos, ora como rudimentos. E, ainda, o que nos parece relevante: esses dois modos de pensar a matemática para os primeiros anos escolares convivem na atualidade.

\section{A matemática nos primeiros anos escolares tem uma história}

Parece ponto pacífico considerar que os saberes matemáticos presentes desde os primeiros anos escolares constituem os passos iniciais para a aprendizagem da matemática. E, ainda, que a matemática dos primeiros anos escolares é a matemática elementar. Como elementar, por extensão, também é considerada toda a matemática presente na escola básica, aquela que reúne todos os graus de ensino anteriores ao ensino superior universitário.

No caso dos primeiros anos escolares podemos dizer que, no âmbito numérico, a matemática elementar compreende ao sistema de numeração decimal, as quatro operações fundamentais. Em termos geométricos, os conteúdos envolvem as primeiras noções de ponto, reta, planos, figuras, sólidos.

Esses saberes elementares permaneceram invariáveis ao longo do tempo?

Uma abordagem da questão leva-nos a investigar o ensino desses saberes elementares em face de diferentes movimentos pedagógicos. Em cada um deles há diferentes modos de conceber a escola, as suas finalidades, a maneira de conduzir 0 ensino, o modo de avaliar a aprendizagem. Em suma: os movimentos pedagógicos caracterizam épocas escolares. Sem recuar demasiadamente no tempo, ao reportarmonos da atualidade a finais do século 19, a História da Educação mostra-nos que estão presentes modos de conduzir a educação os mais diversos. Em cada época, um dado movimento é predominante. Eles são caracterizados por nomes como: pedagogia tradicional, pedagogia moderna, pedagogia ativa, escola ativa, tecnicista, pedagogia intuitiva, pedagogia científica.

Ficariam esses conteúdos ditos elementares - para o âmbito numérico, como se disse, o sistema de numeração e as quatro operações fundamentais; para o geométrico, as primeiras noções de ponto, reta, plano, figuras - sujeitos a essas pedagogias tão somente em termos dos métodos de ensino? Tais conteúdos permaneceriam como invariantes na escola primária, sendo a investigação a ser realizada sobre os saberes matemáticos presentes nos primeiros anos de ensino apenas uma questão de métodos pedagógicos? A matemática escolar - os saberes elementares matemáticos - ditos tradicionais seriam os mesmos que aqueles presentes em tempos do chamado método intuitivo? Haveria alguma diferença entre os saberes elementares matemáticos presentes na escola por ocasião do movimento da Escola Nova relativamente àqueles de tempos anteriores a ela? O Movimento da Matemática Moderna teria deixado intactos os saberes 
elementares matemáticos para os primeiros anos escolares? Em síntese: a história da educação matemática nos anos iniciais seria uma história dos métodos de ensinar os elementares matemáticos vindos de tempos imemoriais?

Tais questões remetem, imperativamente, à necessidade de nos posicionarmos sobre o relacionamento entre pedagogias e os saberes elementares matemáticos ensinados nos primeiros anos escolares.

Um texto que veio em nosso auxílio, para o enfrentamento de tal problemática, ajudando-nos a considerar uma hipótese inicial de trabalho, refere-se ao conhecidíssimo artigo do historiador da educação francês André Chervel, relativo à história das disciplinas escolares. Tirando suas conclusões a partir de estudos que foram realizados sobre a gramática escolar na França, esse pesquisador estabeleceu um marco teórico importante: as pedagogias não constituem tão simplesmente um expediente facilitador, um modo de tornar mais palatável os ensinos. Elas interferem diretamente nos próprios saberes. Dessa maneira, conteúdos de ensino mudam com o tempo, saberes escolares alteram-se com a presença de diferentes pedagogias, de modos diversos de pensar e conduzir a educação. Os conteúdos não são invariantes à espera de métodos vindos das pedagogias. Citando o próprio Chervel, tem-se que

poder-se-ia demonstrar [...] que os 'métodos pedagógicos' postos em ação nas aprendizagens são muito menos manifestação de uma ciência pedagógica que operaria sobre uma matéria exterior do que de alguns dos componentes internos dos ensinos. [...] A pedagogia, longe de ser um lubrificante espalhado sobre o mecanismo, não é senão um elemento desse mecanismo; aquele que transforma os ensinos em aprendizagens (1990, p. 2)

Considerada, então, essa perspectiva teórica, isto é, tendo em conta os estudos de André Chervel como uma hipótese de trabalho, há necessidade de melhor compreender as diferentes pedagogias e investigar de que modo elas produzem e modificam, ao longo do tempo, os saberes elementares matemáticos ensinados nos primeiros anos escolares.

Antes, porém, de analisar os saberes matemáticos a serem ensinados nos primeiros anos escolares em face das pedagogias, caberia uma caracterização das duas categorias presentes desde o título deste estudo: elemento e rudimento. Tal caracterização prévia se faz necessária em termos da exposição deste texto. Verdadeiramente, elas surgiram ao longo do desenvolvimento das pesquisas, e não foram tomadas como um a priori para as análises.

\section{Elementos e rudimentos}

A questão de natureza filosófica relativa à caracterização dos saberes iniciais escolares, daqueles conteúdos que deverão ser ensinados nos primeiros anos, aponta para uma dualidade. Ela está bem posta na síntese interrogativa que realiza o pesquisador Michel Fabre, no prefácio do livro do filósofo da educação Alain Trouvé:

O elementar é uma noção racionalista designando os princípios de uma ciência? Ou trata-se de uma noção empirista que aponta para a gênese do saber? A noção de elementar revela o inteligível ou sensível, ou ainda combinações entre os dois? (Favre in Trouvé, 2008, p. 7) 
Alain Trouvé respondeu sinteticamente à questão do seguinte modo:

Se considerarmos a ideia de elementaridade tomada por si mesma, nós deveremos reconhecer que ela é tradicionalmente referida a uma dada concepção de saber, onde este último se estrutura em "elementos". Ora, isso nos remete à filosofia cartesiana de ter constituído um referente paradigmático desta concepção de saber, origem da noção de saber elementar (Trouvé, 2008, p. 12)

De outra parte, Trouvé lança mão de estudos ligados às doutrinas pedagógicas para expressar ter encontrado uma nova concepção de elementar. $E$ elas também remetem às filosofias:

É, com efeito, no seio do empirismo (de Locke, de Condillac) que é possível compreender como algumas das grandes doutrinas pedagógicas (como as Basedow e de Pestalozzi) inspiraram-se e desenvolveram, por si próprias, uma teoria do saber elementar (Trouvé, 2008, p. 13)

Em conclusão, o autor explica que "há, então, duas fontes filosóficas para a compreensão do saber elementar: uma fonte racionalista e uma corrente empirista, notando-se que elas não resultam no mesmo modelo pedagógico (Trouvé, 2008, p. 13).

No desenvolvimento da síntese acima, considerando as pedagogias, Trouvé destaca que,

esquematicamente, diremos que a pedagogia de tradição racionalista coloca no centro de suas concepções os valores e ideais da Razão e do Saber, enquanto que a pedagogia de tradição empirista privilegia antes de tudo a Experiência e o Sujeito. Nesse sentido, a primeira será mais universal e 'objetivista'; e a segunda, será muito mais particularista e 'subjetivista'. Esta diferença que, de fato, implica numa oposição, permite compreender o fato de que, se as duas tradições estão em acordo quanto ao início das aprendizagens pelos elementos de um saber os mais simples, uma e outra não compartilham da mesma concepção do 'simples' e do 'elementar'. Efetivamente, a primeira considera que o 'simples' reside na abstração, enquanto que a segunda estima que o simples reside na 'concretude'. (Trouvé, 2008, p. 13)

Neste ponto caberia explicitar como essa herança pedagógica dual racionalista/empiricista - se fez presente na caracterização dos saberes matemáticos a serem ensinados nos primeiros anos escolares da escola brasileira. Como foram concebidos esses saberes ao longo do tempo? Que perspectivas estão hoje postas para esses saberes?

Para este estudo, adiante-se, os seus resultados apontam para uma distinção das duas correntes mencionadas acima em termos do que nos foi possível caracterizar como elementar e como rudimentar na análise das fontes de pesquisa. O primeiro termo indica uma herança devedora das Luzes; o segundo caracteriza correntes continuadoras das pedagogias de cunho empiricista. 


\section{Os grupos escolares e a matemática: os elementos}

Foi no final do século 19 que a cidade de São Paulo ganhou expressão maior em seu crescimento econômico e social comparativamente a outros centros como Recife e Rio de Janeiro. E isso em decorrência do êxodo rural, da imigração e do início do processo de industrialização. Além disso,

a modificação do sistema político em 1889 contribuiu para transformações no ensino: a Constituição republicana, consagrando a descentralização político-administrativa, possibilitou o desenvolvimento de iniciativas de âmbito estadual [...]. Com a ideologia republicana, o problema do ensino tornara-se, já antes da queda do Império, uma questão vital para a sobrevivência das instituições políticas. Assim, logo após um curto período de governo por uma junta, o novo presidente estadual indicado pelo governo federal, Prudente de Morais, nomeou em início de 1890 o médico Dr. Antonio Caetano de Campos para a direção da Escola Normal, baixando pouco após um decreto de reforma do ensino normal (Lei de 17 de 12/03/1890). (Souza Campos, 1990, p. 9)

No espírito da reforma, em tempos de Caetano de Campos ${ }^{1}$, uma nova perspectiva de conduzir a educação nos primeiros anos escolares pode ser sintetizada como

partindo dos princípios da pedagogia moderna (especialmente com base em Pestalozzi, Fröebel e Herbart), que insistiam no fato de que ensinar é acostumar a criança a raciocinar por si, fazendo-a descobrir as verdades que lhe são necessárias, Caetano de Campos chegou à conclusão de que os métodos intuitivos eram os melhores. [...] Inicialmente cuidou das condições físicas mínimas que o prédio pudesse abrigar a escola, assim, como a da instalação das escolas-modelo anexas. Concentrou o espírito da reforma na prática que os alunos mestres deveriam ter, nas duas escolas-modelo, uma para cada sexo. (Souza Campos, 1990, p. 9)

Para além da primeira reforma da Escola Normal, Caetano de Campos elaborou, em documento de 1891, um texto entregue ao governador do Estado, no qual sistematizou a sua pedagogia, a organização do ensino em sentido amplo, que deveria ser efetuada em São Paulo.

O texto de Caetano de Campos constitui verdadeira proposta de estruturação da educação paulista em graus de ensino que antecedem a universidade. Seriam três esses graus, precedidos, ainda, de um jardim da infância - kindergarten.

Antes, porém, de anunciar a sua proposta, Campos mencionou o trabalho que vinha sendo feito em São Paulo, no contraponto à herança de tempos anteriores. Campos recorreu ao passado, construindo-Ihe uma representação negativa para introduzir o novo, os novos métodos, as novas propostas republicanas paulistas:

Temos ouvido dizer até a saciedade que é indispensável difundir o ensino elementar. Ninguém o nega, nem pode negar. Começa-se por saber ler, escrever e contar, e sem este primeiro passo todo o ensino é impossível.

\footnotetext{
${ }^{1}$ Antonio Caetano de Campos, médico de formação, foi nomeado diretor da Escola Normal de São Paulo, indicado por Rangel Pestana ao governador do estado Prudente de Morais. Sua tarefa principal foi a de realizar a reforma da Escola Normal. Tal obra foi colocada em prática entre janeiro de 1890 e setembro de 1891. A morte prematura de Caetano de Campos, em 12 de setembro de 1891, deixou sua obra apenas iniciada, sem que pudessem ser estabelecidos os graus subsequentes aos primeiros anos escolares pensados por Campos, descritos no relatório enviado ao governador meses antes de seu falecimento.
} 
Isto é questão vencida, sobre a qual não é preciso insistir. A experiência de 70 anos de monarquia demonstra, porém, que este famoso lema pode ser reduzido a uma inutilidade. Não só a proporção das escolas primárias criadas no tempo dos imperadores é extremamente ridícula, em vista das exigências da população, como sua frequência é irrisória. É inútil buscar a causa deste insucesso na índole do povo. Com o ignorante é demência argumentar. O povo não podia conhecer a vantagem de aprender, porque via que seus filhos, apesar de andarem na escola, nenhum desenvolvimento mental adquiriam. Esse vício, esse erro, esse non sense provinha dos métodos empregados no ensino. As crianças decoravam tudo, para em breve tudo esquecer. Fatigavam-se sobre as cartas de leitura, só conseguindo entediar-se por não entenderem o que liam. Revoltavam-se finalmente no seu íntimo por ouvirem-se apelidar de estúpidos, quando só revelava estupidez quem Ihes fornecia um alimento que elas não podiam digerir. (Annuario, [1908], p. 104)

A esse passado considerado tão pouco elogiável do ensino elementar, tão condenável em seus métodos inadequados, Caetano de Campos revelou o bom andamento das mudanças que estavam em marcha na cidade de São Paulo, no ensino primário.

Considerando todo o sucesso apregoado por Caetano de Campos, no que se refere aos ensinos dos primeiros anos escolares, o autor advoga a continuidade dos estudos. Esse é o foco central dos seus escritos: sensibilizar o governo para uma reforma ampla, pela qual fosse possível estabelecer vários graus a antecederem o ensino superior. Há que ser estabelecido um sistema graduado para acesso aos saberes mais plenos, avançados. A seguir, expressa o que entendia ser o papel da escola diante do conhecimento:

É, em meu fraco entender, indiscutível que o ensino útil, positivo, lógico, sem prevenções de seita ou de classes, aquele que é julgado bom segundo a ciência pura e a experiência dos antepassados, deve existir em qualquer parte. Ainda mais, que para que esse ensino seja profícuo deve, quanto possível, ser completo, inteiro em todos os ramos de conhecimentos indispensáveis à vida, enciclopédico por assim dizer, já que nosso viver social na atualidade envolve-nos em contingências oriundas de toda sorte de noções científicas. (Annuario, [1908], p. 105)

Campos questionava a terminalidade dos estudos do curso primário, advogando escolas secundárias:

O que faltou sempre e nos falta ainda, é a instrução intermediária que só em escolas secundárias poderá obter-se. Se o ensino primário é indispensável ao homem, ele o é para algum fim. Esse não pode ser outro senão o de adquirir nos livros os conhecimentos que lhes são indispensáveis. Ora, deixar a criança, aos 10 anos - limite que nossa lei marca para o ensino primário - com os rudimentos de uma instrução, que por falta de bons guias ela não poderá mais obter - senão excepcionalmente, é caso muito para lamentar-se. (Annuario, [1908], p. 106)

Sem muito extrapolar a análise das citações de Campos, é possível afirmar-se que seus argumentos estão sempre acostados à referência dos saberes científicos. Para além disso, mostra que a progressão, a continuidade é fundamental face aos primeiros passos 
adquiridos nos anos de curso primário para a formação do que chama o homem útil. E, de modo emblemático, advoga o leque enciclopédico de saberes. Os saberes adquiridos no curso primário necessitam de continuidade, não bastam. E esses saberes devem ter continuidade no ensino secundário:

A Escola de $2^{\circ}$. grau é a que segue-se à do ensino primário. Abrange a idade que vai dos 10 até os 15 anos. Os meninos estão, pois, na melhor idade para aprender, e só então se lhes pode dar uma verdadeira base de instrução, porque nas escolas de $1^{\circ}$. grau só têm adquirido algum hábito de trabalho intelectual, a vantagem da leitura, escrita e princípios do cálculo, junto com algumas noções do mundo exterior. A escola de $1^{\circ}$. grau é, pois, um preparo para a do $2^{\circ}$. (Annuario, [1908], p. 111)

A citação acima esclarece a natureza dos saberes adquiridos no curso primário: deverão ser propedêuticos, preparatórios para os do ensino secundário. Para além disso, tais saberes desenvolvem hábitos intelectuais. No que mais diretamente toca ao contar, leva os alunos a adquirirem alguns princípios do cálculo.

A ordem proposta dos saberes, da continuidade nos diferentes graus de ensino, não promove ruptura entre eles. Isto é, a ordem pedagógica dos ensinos deverá seguir a ordem epistemológica dos saberes científicos.

Toda a proposta de Caetano de Campos, de estruturação do ensino em São Paulo, argumentada no documento enviado ao governador do Estado, no entanto, não se realizou em decorrência de sua morte prematura. Campos morreu no mesmo ano de 1891. Uma nova reforma foi proposta em 1892, mas com caráter diferente daquele de Caetano de Campos. Os cursos de segundo grau passaram a constituir um curso complementar, após o elementar primário (Souza Campos, 1990). Assim, a ideia de graduação, de ensino propedêutico, que articularia o primário ao secundário, permaneceu em sua essência.

As propostas de Caetano de Campos parecem expressar a concepção iluminista de conceber o elementar, os saberes elementares. Por certo, fruto de múltiplas apropriações que o distanciamento e contextos de elaboração das propostas para estruturação do ensino paulista permitiram. Mas tendo concebido os saberes elementares como propedêuticos e a integração enciclopédica deles, como pretendia Campos, revela heranças iluministas. Nada mais em acordo com os projetos republicanos de tratar a Educação: a liberdade vinda da instrução pela ciência. As propostas de Campos revelam o elementar para os primeiros anos escolares, o simples em termos de continuidade para o acesso aos saberes mais elaborados. Como se disse, a ordem pedagógica segue a ordem epistemológica dos saberes científicos. E isso é reafirmado no próprio texto, quando Campos se refere à matemática dos primeiros anos escolares:

A disciplina matemática também gradualmente sistematizada aumenta a clareza do raciocínio. Dantes, considerava-se mesmo o cálculo como a melhor forma educativa da inteligência. Hoje percebe-se, porém, claramente que o número e a forma são apenas duas faces das questões que o espírito pode ser chamado a aquilatar. Saber calcular não basta, pois, para saber verificar as leias da natureza. (Annuario, [1908], p. 112) 
Os primeiros passos na matemática tem por consequência o desenvolvimento do raciocínio do aluno, dar-lhe, no seu modo de ver, algum hábito de trabalho intelectual. Assim, uma das facetas da apropriação da herança iluminista realizada por esse autor refere-se à conjugação do método intuitivo como etapa inicial, grau primeiro para a escalada aos saberes elaborados, que farão parte da instrução no $2^{\circ} \mathrm{grau}$, no $3^{\circ} \mathrm{grau}$ e, por fim, do ensino superior.

\section{A escola ativa e a matemática: os rudimentos}

A década de 1920 no Brasil é pródiga em reformas educacionais. Ainda sem organização de um sistema de educação pública, sem a existência de um ministério da educação, coube aos diferentes cantos do país a formulação de reformas com vistas a organizar e modernizar o ensino. Em 1920, Sampaio Dória, em São Paulo, deu início a essas ações de caráter regional. Segue-se, cronologicamente, o trabalho de Lourenço Filho no Ceará entre 1922-23; em 1924, foi a vez da Bahia com Anísio Teixeira. Outros locais como Rio Grande do Norte, Paraná e Minas Gerais promoveram, também nesse tempo, as suas reformas educacionais. No entanto, a reforma empreendida por Fernando de Azevedo é considerada uma das mais importantes e de maior impacto para a educação. Azevedo elaborou a reforma do ensino no Rio de Janeiro, então capital da República, entre os anos de 1927 a 1930.

Muitos são os estudos acerca da reforma promovida por Fernando de Azevedo no Rio de Janeiro. Há trabalhos que, inclusive põem em perspectiva a variada gama de textos elaborados por historiadores da educação, tendo por referência as ações reformistas de Azevedo ${ }^{2}$. O trabalho de Fernando de Azevedo é considerado um marco fundamental no processo de modernização da escola brasileira.

Como se mencionou a princípio, o presente texto atém-se a uma análise possível de ser feita sobre as ideias desse educador relativamente aos saberes escolares, com foco na matemática a ser ensinada nos primeiros anos de ensino. Iniciemos, pois, a análise do discurso de Fernando Azevedo sob esse prisma.

Sob o título de Programas das escolas do Distrito Federal a Revista Escola Nova, em seu volume 1, números 2 e 3, de novembro e dezembro de 1930, publicou longo texto de Fernando de Azevedo. Muito mais do que tratar de programas de ensino, o autor divulgou, em meio aos professores, o texto da reforma e praticamente todo o ideário que embasou as ações por ele conduzidas e elaboradas para a instrução pública do Rio de Janeiro, Distrito Federal:

A nova reforma de ensino inspirou-se, com se conclui de todas suas disposições fundamentais, no propósito de dar à escola uma consciência profunda de sua tarefa social e nacional e de a aparelhar dos meios necessários à realização dessa tarefa poderosamente educadora, tanto pela intensidade, como pela extensão de sua influência. (Azevedo, 1930, p. 196)

${ }^{2}$ Veja-se, por exemplo, o estudo de Paulilo (2010). 
É na terceira parte do texto de Fernando de Azevedo, no item Novos fins, novos meios, que o autor tratou dos programas de ensino. Para tal, realizou, à certa altura, uma comparação dos novos meios, diante dos novos fins escolares, relativamente àquilo que toma por modo de pensar os programas antes da sua reforma:

$\mathrm{Na}$ escola antiga, o aluno começa por aprender "exprimir" (linguagem, cálculo etc.) o material que dava o professor e que ele não tinha mais que aprender e fixar. Na escola nova, ele deve "exprimir" o que observou. O trabalho - ponto capital para onde convergem todas as linhas do novo plano de organização escolar, e, portanto, um dos princípios por que se orientam os novos programas, - satisfaz a tendência e a necessidade de aluno de "exprimir-se" e de afirmar-se. A linguagem (oral, escrita e musical), o desenho, o trabalho manual (especialmente a modelagem), ou, por outros termos, a palavra, a linha e a matéria prima (a massa plástica, por exemplo) são os grandes elementos de expressão. O desenho e os trabalhos manuais, na escola do trabalho, baseada sobre a atividade pessoal do aluno, têm o grande relevo que lhes dá a finalidade da educação orientada para os novos ideais. (Azevedo, 1930, p. 206)

Depois do texto introdutório da reforma, seguem os programas, sob o título Programa para as escolas primárias - Instruções.

Para as finalidades do presente estudo, iremos no deter, especificamente, no item Iniciação Matemática. Diz o texto que

a cultura científica adquirir-se-á na escola primária apenas nos seus rudimentos de ordem geral, a que se costuma chamar de iniciação, rudimentos esses que, visando utilidades de aplicação na vida, não podem ser considerados como ciência no sentido rigoroso da palavra. (Azevedo, 1930, p. 224)

Tal citação é emblemática para as finalidades do presente estudo. Algumas observações cabem desde já. Uma primeira delas diz respeito à caracterização do significado de iniciação. No dizer do autor, iniciação corresponde ao acesso aos rudimentos. E tais rudimentos não é similar à ideia de elementos, das primeiras partes simples de um saber avançado, de um saber científico. No mais, o próprio autor destaca que tais rudimentos não podem ser vistos como ciência. Rudimentos indicam as partes úteis para a vida prática, a vida de todos os dias.

A importância do que é ensinado nos primeiros anos escolares para a vida prática é sempre reiterada na reforma. Isso pode ser lido nas instruções sobre as matérias Aritmética e Geometria:

Procurando sempre fazer com que o ensino da Aritmética e da Geometria, como aliás, o das demais disciplinas, decorra da vida prática e a ela se prenda, o professor o encaminhará de modo que produza nos alunos justo equilíbrio entre o raciocínio e o cálculo mental ou escrito, ligando-os objetivamente a fenômenos de representação concreta, partindo do exemplo para o preceito do fato para a explicação de princípios, dos problemas de vida quotidiana para as noções abstratas (1930, p. 224)

Essas considerações são exemplificadas no próprio trato com os problemas aritméticos a fazerem parte dos ensinos: 
Foge ao espírito da nova pedagogia o uso sistemático de problemas formulados dogmaticamente pelo mestre e que acabam tomando a forma de paradigmas que se prestam a ser aproveitados mecanicamente em outros casos, com a mera substituição de dados quantitativos ou qualitativos. [...] Caberá ao mestre mostrar a solução ou o encaminhamento que na vida prática os técnicos (negociantes, industriais, lavradores) dão mais frequentemente a tais questões). (1930, p. 226)

Em face dessas citações é possível inferir que o papel dos saberes envolvidos nos primeiros anos escolares, para além da ênfase na metodologia, reveste-se de uma significação pedagógica clara e diversa da ordem epistemológica dos saberes científicos: nos primeiros anos escolares trabalhar-se-á com os rudimentos. Somente os rudimentos poderão se articular com os problemas da vida cotidiana. Com eles forma-se o aluno que aproveita a parte útil e transferível do saber para a vida comum. Não se trata de iniciar o aluno no percurso da ciência, dando-lhes os elementos de cada saber avançado. A escola dos primeiros anos é prática, tem caráter terminal e precisa usar o seu tempo formativo para melhor municiar os alunos que dela saírem com os instrumentos úteis à vida de cada um.

Os saberes matemáticos deverão ser os rudimentos matemáticos que se prestam à melhor condução da vida comum. Não constituem os elementos de uma aritmética, de um cálculo mais avançado ou mesmo de uma geometria. Não têm ligação ou encadeamento com os saberes elementares da escola secundária. São rudimentos para uma escola terminal, modos de manejar cálculos, operar com o sistema de pesos e medidas. Instruções para viver melhor no seu meio, para se beneficiar do conhecimento útil vindo das ciências.

\section{Tempos atuais: rudimentos ou elementos?}

Se os primeiros tempos da escola republicana no Brasil, que têm por ícone a criação dos grupos escolares, apropriaram-se da herança iluminista, concebendo os saberes da escola primária e aqueles matemáticos como elementos, como visto no ideário enunciado por Caetano de Campos, no âmbito do movimento pedagógico do ensino intuitivo, e, ainda, se três décadas depois, com a referência da Escola Nova, da pedagogia ativa, os saberes elementares, a matemática dos primeiros anos escolares são tidos como um conjunto de rudimentos, como se viu no discurso de Fernando de Azevedo, pergunta-se: como os tempos atuais reelaboraram essa herança pedagógica? Como esses discursos pedagógicos foram apropriados em época recente?

Antes, porém, de nos reportarmos à atualidade, caberia, mesmo que de modo breve, de maneira a não estender em demasia o presente estudo, evocar um ponto que parece de viragem da tendência escolanovista de abordar como rudimentos os saberes da escola 
primária. Destaque-se que o escolanovismo permaneceu como referência por praticamente por toda a primeira metade do século 20 no Brasil. Caberia evocar o Movimento da Matemática Moderna ${ }^{3}$.

Os finais da década de 1950 indicam uma preocupação com a matemática escolar, sem par, talvez, com outras matérias escolares. Busca-se uma matemática escolar moderna. Algo como uma retomada do elementar matemático iluminista: os gérmens do saber matemático estando presentes desde os primeiros anos escolares. $O$ encadeamento pedagógico dos conteúdos seguindo a ordem epistemológica do saber matemático. As primeiras noções da teoria dos conjuntos, por exemplo, atestam essa observação. Desde os primeiros anos escolares os alunos deveriam aprender os primeiros passos das estruturas algébricas. Mesmo que essa nova matemática mostrasse sua configuração circundada pela psicologia cognitiva, os seus elementares não estavam definidos pela empiria do sujeito que aprende. O sujeito piagetiano constituía-se transcendendo as condições e conjunturas locais: um sujeito geral, ideal. E a nova matemática subordinou-se, na escola, àquela mais avançada, tida como um elementar para acesso à matemática superior.

Se assim foi, constata-se, até aqui, uma alternância no modo de conceber os saberes matemáticos a serem ensinados nos primeiros anos escolares: como elementares, no ideário republicano paulista; como rudimentares, nas referências escolanovistas; novamente como elementares, nas propostas de mudanças da matemática para uma matemática moderna. Nestes termos, retome-se a questão: que heranças a matemática dos primeiros anos escolares revela em tempos atuais? Elementos ou rudimentos para o ensino de matemática?

Constituído o campo da Educação Matemática ${ }^{4}$, em finais dos anos 1980, com o refluxo do Movimento da Matemática Moderna, ao que parece, atenta-se, novamente, para o sujeito que aprende: novas bases empiristas de realização das pesquisas sobre a matemática escolar põem-se em marcha. Um tema emblemático dessa retomada é a recuperação da geometria euclidiana, ícone da discórdia em tempos de matemática moderna. Essa recuperação revela uma ruptura relativamente a um dos argumentos importantes contidos nas propostas de elaboração de uma matemática moderna: a de que caberia ensinar-se uma matemática viva, isto é, uma matemática que fosse atual, passível de pesquisas matemáticas. Assim, desde os primeiros anos, estariam presentes os gérmens da matemática superior, fruto de pesquisa dos matemáticos: os seus elementos! Esse argumento alijava a geometria euclidiana por tratar-se de saber matemático morto, não mais passível de pesquisa matemática. A geometria euclidiana

\footnotetext{
${ }^{3}$ Muitos são os estudos existentes sobre o MMM. Um número diminuto, porém, trata da matemática dos primeiros anos escolares sob essa vaga pedagógica. Cite-se, dentre eles, o texto A matemática moderna para crianças, escrito coletivamente por Aparecida Rodrigues Silva Duarte, Denise Medina França, Lucia Maria Aversa Villela e Rosimeire Aparecida Soares Borges, que constitui o capítulo quarto da obra $O$ movimento da matemática moderna: história de uma revolução curricular, organizado por Maria Cristina Araújo de Oliveira, Maria Célia e Leme da Silva, Wagner Rodrigues Valente (2011).

${ }^{4}$ Para uma discussão aprofundada sobre o assunto leia-se o texto de MIGUEL, Antonio; GARNICA, Antonio Vicente Marafioti; IGLIORI, Sonia Barbosa; D’AMBROSIO, Ubiratan. A educação matemática: breve histórico, ações implementadas e questões sobre sua disciplinarização. Revista Brasileira de Educação, n. 27, 2004, p. 70-93.
} 
não levaria à matemática superior. Assim, a Educação Matemática vinha a demonstrar que se a geometria euclidiana não tem valor matemático, pois não mais constitui-se em campo de pesquisa, tem ela valor inestimável do ponto de vista formativo, educativo ${ }^{5}$.

Uma breve leitura dos objetivos do ensino dos números e operações no documento Elementos conceituais e metodológicos para definição dos direitos de aprendizagem e desenvolvimento do ciclo de alfabetização (1, 2 e 3 anos) do Ensino Fundamental (Brasil, 2012), revela uma perspectiva herdeira do empirismo, do respeito aos modos do sujeito aprender, afastando-se de sequências e ordens lógicas de conteúdos a serem ensinados, em conformidade com lemas defendidos pela Educação Matemática. Leia-se, por exemplo, o primeiro e emblemático objetivo: "I - Utilizar caminhos próprios na construção do conhecimento matemático, como ciência e cultura construídas pelo homem, através dos tempos, em resposta a necessidades concretas e a desafios próprios dessa construção" (Brasil, 2012, p. 66).

Os tempos atuais, de educação matemática, mais recentemente, convivem com o ensino de matemática. Entre nós, e em todos os países de língua portuguesa, se divulga o Klein Project, por meio do sítio http://klein.sbm.org.br:

O Projeto Klein de Matemática em português vai coordenar e organizar a contribuição do Brasil ao Klein Project for the 21st century, além de articular a colaboração nesta área com pesquisadores, professores $e$ educadores dos demais países de língua portuguesa, para ampliar de forma substancial o alcance dos resultados. Outro objetivo central do projeto é a produção de material bibliográfico em língua portuguesa que seja de efetiva utilidade para o ensino da matemática em todos os níveis. (Projeto Klein)

Dentre os objetivos do projeto inclui-se

produzir um livro de leitura acessível, mas profissional, que transmita a conexão, crescimento, relevância e a beleza da disciplina Matemática, desde suas grandes idéias a fronteiras da pesquisa e aplicações. Este livro será disponibilizado em várias línguas, incluindo o português. (Projeto Klein)

Nesses termos, os tempos atuais parecem querer recuperar o elementar matemático iluminista. Assim, novamente, assiste-se a uma tendência de alternância: do rudimentar para o elementar.

\section{Considerações finais}

Como se mencionou desde o início deste estudo, seu objetivo consiste em divulgar resultados de pesquisa de projetos em andamento. Tais resultados evocam como são concebidos os saberes matemáticos para serem ensinados nos primeiros anos escolares ao longo do tempo. Por certo, cada época escolar, no âmbito das pesquisas, tem extensa discussão e debate relativamente à caracterização dos saberes. O texto subtrai tais debates por força de limitação de espaço. Na síntese que é possível elaborar, este texto trata, de início, do discurso de Caetano de Campos, representante importante da escola

\footnotetext{
${ }^{5}$ Veja-se o capítulo 3 - La géométrie, do livro dirigido por Kahane (2002). 
republicana paulista, modelo que se expandiu para os demais Estados da federação. Sua concepção aproxima-se de uma reelaboração da herança iluminista, sendo os saberes matemáticos dos anos iniciais vistos como elementos.

Em tempo posterior, Fernando Azevedo, um dos ícones da Escola Nova, revelou a sua concepção de rudimentos para o ensino nos primeiros anos escolares: e os rudimentos não representam elementos. Nota-se que se atrelam diretamente às necessidades de articulação de temas úteis do conhecimento elaborado, com as necessidades da vida social, cotidiana. Uma primeira alternância revelou-se: dos elementos para os rudimentos no trato com a matemática escolar para os primeiros anos, na passagem da vaga intuitiva para a escolanovista.

Mesmo de modo breve, sem estender a análise, aborda-se o Movimento da Matemática Moderna, tema de muitos estudos já realizados nos últimos anos. E para esta novo modo de pensar a matemática para os anos iniciais há a recuperação da herança iluminista: cabe reelaborar a matemática escolar de modo a que ela tenha uma articulação direta com a matemática superior $e$, àquele tempo, com as estruturas algébricas. Novos conteúdos foram incorporados ao ensino. A teoria dos conjuntos constitui conteúdo emblemático. Caberia, desde os primeiros anos escolares, prover os alunos dessa nova linguagem que expressa a matemática estruturalista. Trata-se do encadeamento da matemática dos primeiros anos para aquela avançada: os elementos. Assim, nota-se nova alternância: dos rudimentos escolanovistas para os elementos da matemática moderna.

Os tempos atuais, sempre muito difíceis de serem abordados historicamente, têm neste texto, tratamento também abreviado. No entanto, mesmo assim, é possível dizer que desde a década de 1980 há o surgimento de uma nova perspectiva para a matemática escolar: a Educação Matemática. No contraponto com o MMM, essa perspectiva, hoje orientadora de programas de pós-graduação, de referências curriculares, de cadeiras de formação dos futuros professores de matemática dentre outras influências, parece ter retomado, para os anos iniciais, noutros termos por certo, a ideia de rudimentos para os saberes matemáticos presentes nos anos iniciais.

Mais recentemente ainda, menciona-se a divulgação do Klein Project. Pensar novamente a matemática elementar do ponto de vista superior retoma o projeto iluminista para os saberes escolares.

Por fim, cabe enfatizar, convive-se, hoje, em termos da matemática dita elementar, com dois modelos herdeiros das duas perspectivas fundamentais referidas no início: 0 racionalismo das Luzes e o empirismo evolucionista do século 19. E, nestes termos, vale uma frase já dita por muitos autores: o passado está sempre presente.

\section{Referências}

ANNUARIO do ensino do Estado de São Paulo (1907-1908). Publicação organizada pela Inspectoria Geral do Ensino por ordem do Governo do Estado, São Paulo: Augusto Siqueira \& C., [1908]. Disponível em <https://repositorio.ufsc.br/handle/ 123456789/96644>. Acesso em 10 fev. 2015.

AZEVEDO, Fernando. Programas das escolas do Distrito Federal. Revista Escola Nova, v.1, n. 2-3, 1930. 
BRASIL. Elementos conceituais e metodológicos para definição dos direitos de aprendizagem e desenvolvimento do ciclo de alfabetização (1, 2 e 3 anos) do ensino fundamental. Brasília: MEC/SEB, 2012.

CAMPOS, Caetano de. Relatório apresentado ao Governador do Estado de São Paulo, Prudente de Moraes em $1^{\circ}$ de março de 1891. Annuario do Ensino do Estado de São Paulo, 1907-1908. Disponível em <http://repositorio.ufsc.br/xmlui/handle/ 123456789/96644>. Acesso em 14 jan. 2015.

CASTRO, Rosane Michelli de. A história da educação em São Paulo: a instrução pública dada a ler nos Annuarios do ensino do estado de São Paulo (1907-1927). Revista Brasileira de História da Educação. Campinas, v. 12, n. 2, 2012, p. 209-238.

CHERVEL, André História das disciplinas escolares: reflexões sobre um campo de pesquisa. Teoria \& Educação, n. 2, 1990, p. 177-229.

KAHANE, Jean-Pierre (dir.). L'enseignement des sciences mathématiques. Paris: Odile Jacob, 2002.

MIGUEL, Antonio; GARNICA, Antonio Vicente Marafioti; IGLIORI, Sonia Barbosa; D'AMBROSIO, Ubiratan. A educação matemática: breve histórico, ações implementadas e questões sobre sua disciplinarização. Revista Brasileira de Educação, n. 27, 2004, p. 7093.

PAULILO, André Luiz. Uma historiografia da modernidade educacional. Estudos Históricos. Rio de Janeiro, v. 23, n. 45, 2010, p. 27-49.

OLIVEIRA, Maria Cristina Araújo de, LEME DA SILVA, Maria Célia, VALENTE, Wagner Rodrigues (org.). O movimento da matemática moderna: história de uma revolução curricular. Juiz de Fora: UFJF, 2011.

PILETTI, Nelson Fernando de Azevedo. In: FÁVERO, Maria de Lourdes de Albuquerque (org.). Dicionário de educadores no Brasil: da colônia aos dias atuais. Rio de Janeiro: UFRJ/MEC, 1999.

PROJETO KLEIN. Projeto Klein de matemática em língua portuguesa. Disponível em $<$ http://klein.sbm.org.br>. Acesso em 6 fev. 2015.

SOUZA CAMPOS, Maria Christina Souza Campos. Formação do magistério em São Paulo: do Império a 1930. Cadernos de Pesquisa. São Paulo, n. 72, 1990, p. 5-16.

TROUVE, Alain. La notion de savoir élémentaire à l'école. Paris: L'Harmattan, 2008.

WAGNER RODRIGUES VALENTE é professor livre docente do Departamento de Educação da Escola de Filosofia, Letras e Ciências Humanas da Universidade Federal de São Paulo - campus de Guarulhos.

Endereço: Rua do Rosário, 382 - 07111-080 - Guarulhos - SP - Brasil.

E-mail: wagner.valente@unifesp.br.

Recebido em 25 de junho de 2015.

Aceito em 7 de novembro de 2015. 